\title{
La crítica de la psicología, trabajo y la pandemia de Covid-19^
}

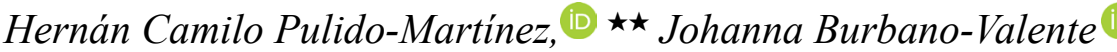 \\ Pontificia Universidad Javeriana, Bogotá, Colômbia
}

\begin{abstract}
Resumen
Ante la pandemia de Covid-19 causada por el virus SARS-CoV-2 que puso a los trabajadores de la región lationamericana en una condición de mayor vulnerabildad, en este artículo se consideran algunas de las respuestas proporcionadas por la psicología convencional de corte industrial-organizacional, las cuales han estado caracterizadas por su enfasis técnico y acritico dirigido a responsabilizar a los trabajadores de la actual situación. Tambien son analizadas las propuestas construidas por la psicología crítica descritas como soluciones colectivas que convocan instancias Estatales, organizacionales, sindicales y gremiales para diseñar intervencinoes que contribuyan a mitigar la situacion de mayor vulnerabilidad laboral. Por último, son consideradas las respuestas derivadas de perspectivas externas a la psicologia que examinan criticamente esta disciplina para mostrar las operaciones de gobierno que son posibles gracias a las intervenciones psicológicas referidas a la contencion de la pandemia. Se señala que la llamada crisis de la crítica estaría permeándose tanto en aquellas psicologías que asumen perspectivas no hegemónicas, como en la crítica misma de la psicología cuando consideran la situación actual.
\end{abstract}

Palabras clave: psicología crítica; psicología del trabajo; crisis de la crítica.

\section{A crítica da psicologia, trabalho e a pandemia de Covid-19}

\section{Resumo}

Diante da pandemia da Covid-19 causada pelo vírus SARS-CoV-2, que colocou os trabalhadores da região latino-americana em uma condição mais vulnerável, neste artigo se considera algumas das respostas fornecidas pela psicologia convencional, que tem se caracterizado por sua ênfase técnica e acrítica no sentido de responsabilizar os trabalhadores pela situação atual. Também se analisam as propostas construídas pela psicologia crítica descritas como soluções coletivas que apelam às instâncias estatais, organizacionais, sindicais e grupais para conceber intervenções que ajudem a mitigar a situação de maior vulnerabilidade no trabalho. Por fim, são consideradas as respostas derivadas de perspectivas externas à psicologia que examinam criticamente essa disciplina para mostrar as operações de governo que são possíveis por meio de intervenções psicológicas relacionadas à contenção da pandemia. Ressalta-se que a chamada crise da crítica estaria permeando tanto aquelas psicologias que assumem perspectivas não hegemônicas, como a própria crítica da psicologia em si ao se considerar a situação atual.

Palavras-chave: psicología crítica; psicología do trabalho; crise da crítica.

\section{The criticism of psychology, work, and the Covid-19 pandemic}

\begin{abstract}
Faced with the Covid-19 pandemic caused by the SARS-CoV-2 virus that put workers in the Latin American region in a more vulnerable condition, this article considers some of the responses provided by conventional industrial-organizational psychology, which have been characterized by their technical and uncritical emphasis aiming at holding workers accountable for the current situation. Also, the proposals constructed by critical psychology are analyzed to indicate that these collective solutions appeal to State, organizational, union and group instances to design interventions that contribute to mitigate the situation of greater vulnerability at work. Finally, the responses derived from perspectives external to psychology that critically examine this discipline are considered to show the government operations that are possible through psychological interventions related to the containment of the pandemic. It is pointed out how the so-called crisis of criticism is permeating those psychologies that assume non-hegemonic perspectives, as well as in the criticism of psychology itself when they consider the current situation.
\end{abstract}

Keywords: critical psychology; work psychology; crisis of criticism.

\section{Introducción}

La crisis de la crítica en el mundo académico es objeto de debate. En efecto tal como se señala en la literatura, en los últimos años parecen cada vez más limitadas las posibilidades que se tienen para que el ejercicio crítico tenga un lugar y produzca unos resultados (FASSIN, 2019). El avance de la empresarialización de la Universidad, con la consecuente marginalización de las perspectivas al-

^Fonte de financiamento: Vicerrectoría de Investigación Pontificia Universidad Javeriana, Bogotá. Proyecto ID: 00004234.

$\star \star$ Endereço para correspondência: Pontificia Universidad Javeriana. Carrera 7 No.40-00, Bogotá, Colombia.E-mail: cpulido@javeriana.edu.co, jburbano@ javeriana.edu.co

Os dados completos dos autores encontram-se ao final do artigo. ternativas; la injerencia que gana el sector privado de la economía en los temas de investigación reservados a las disciplinas; así como la apropiación que se han dado de las maneras de hacer la crítica, otrora transformadoras, empero ahora vueltas contra sí mismas por las formas populistas y conservadoras de hacer política, ha llevado a formular que la crítica se halla en estado de crisis (FASSIN, 2019). En medio de este panorama, este artículo se propone como objetivo volver sobre la psicología en su relación con el trabajo. Más específicamente, se ocupa de examinar la llamada crisis de la crítica en su manifestación en las psicologías que asumen perspectivas al- 
ternativas, así cómo en la crítica misma de la psicología, cuando consideran el presente entorno suscitado por el Covid-19 en la región Latinoamericana.

Vale empezar por señalar el lugar de la crítica antes de que emergiera la pandemia. En términos acertados Fassin (2019) ya había descrito que, en la Universidad otrora el bastión del pensamiento progresista de la sociedad, los puestos de trabajo de los académicos profesantes de estas perspectivas estaban siendo recortados. Por doquier, desde distintas instancias, estatales, empresariales, universitarias y en las mismas asociaciones gremiales, abiertamente se pedía que se restringieran los cargos académicos y se recortaran los presupuestos para la investigación de corte crítico. La política institucional que se imponía veía un desperdicio de recursos, en mantener programas y tópicos que no pudiesen traducirse, bien en educación para el trabajo tecnocrático, o bien para que tuviesen repercusión en algún tipo ganancias monetarias (IBARRA-COLADO, 2006; DELANTY, 2001). De este modo, el papel de crítica de la sociedad que tradicionalmente se le había asignado a la Universidad, estaba cambiando, para ahora tomar el rumbo de convertirse en una institución más de corte politécnica, con el aplauso de muchos limitada a la "provisión de manos" para el mercado laboral (PULIDO-MARTINEZ, 2019). En este panorama, a las humanidades se las relegaba a un punto inerte en los programas académicos y, en algunos casos se formulaba que debían desaparecer de las opciones que se ofrecían para la formación de los estudiantes. Asimismo, como estrategia, a la crítica con mayor tinte radical se la marginalizaba de modo tal que se le daba expresión en carreras en donde no tenía mayor figuración, ni resonancia social (FASSIN, 2019). Muy esquemáticamente se podría afirmar que, a la crítica se le toleraba cada vez menos, y se le hacía cada día menor caso, esperando que en algún momento llegara, por este proceso, a agotarse. En este panorama al esfuerzo crítico en la psicología no se le podía atribuir nada especial que lo hiciera inmune a la anunciada crisis. Como en las demás ciencias sociales estaría cimentándose una situación de vulnerabilidad que podría estar poniendo en peligro su existencia.

En la actualidad ante la pandemia, ha ocurrido un fenómeno que no pasa desapercibido en relación con la crisis de la crítica, las recomendaciones que se han formulado, desde las ciencias que se apoyan en la evidencia en relación con la salud, han sido públicamente puestas en cuestión por el populismo de derecha y de izquierda, tanto en países centrales como periféricos (CHRISTIE; LANZA; CAMILLERI, 2020). Estrategias similares a aquellas que relegan los ejercicios críticos a un segundo lugar, han sido utilizados para invalidar las opiniones que provienen de la ciencia (CHRISTIE; LANZA; CAMILLERI, 2020). Por otro lado, resulta llamativo la circulación de la crítica que ha tenido lugar a raíz de que distintos académicos hayan puesto rápidamente de presente sus análisis acerca de la situación particular. Circulan por las redes escritos de figuras renombradas que se identifican con el pensar critico en donde sus análisis anuncian, por ejemplo, cambios radicales en el sistema capitalista y en el mundo del trabajo. De estas propuestas como sugiere Fassin (2019), habría que mantenerse un tanto distante, pero a la vez informado, en la medida en que ellas al tener un carácter reactivo ante los eventos, pueden sin intención contribuir a debilitar aún más el esfuerzo crítico (AGAMBEN et al., 2020). Estas posiciones parecieran estar en concordancia, por un lado, con el desconcierto que ha desatado la expansión de pandemia de Covid-19; y por otro, con la crisis misma de la crítica que en una suerte de futurología rápida deja de lado el conocimiento que se ha logrado en distintos campos entre ellos los correspondientes a la investigación biológica y epidemiológica. En esta misma línea del debilitamiento de la crítica, es al menos llamativo que ahora se clame en muchas de las huestes alternativas por las libertades individuales, cuando antes se les veía como problema. Así como también, que hoy en día se deje entrever un cierto protagonismo intelectual responsivo destinado a audiencias ávidas de la crítica que aplauden estos ejercicios aprontados y públicos de la razón.

Toda crisis social afecta al mundo del trabajo, es imposible que esto no ocurra. La presente emergencia sanitaria, por tanto, no se constituye en una excepción. Por el contrario, el trabajo es el centro de las consideraciones que se hacen. Baste decir que las medidas que se toman por parte de las entidades gubernamentales para restringir la expansión del virus, y a la vez para mantener funcionando a la economía, giran en mayor medida en torno al trabajo, las empresas y los trabajadores. En este panorama a la psicología se le interroga pidiéndole una suerte de intervenciones para enfrentar la crisis laboral que tiene muy distintas dimensiones.

En este artículo se va a considerar, especificamente, cómo a raíz de las relaciones que tanto la psicología hegemónica como las perspectivas críticas han asumido con respecto al mundo trabajo se pueden interrogar las prescripciones que se han formulado para dar respuesta a la pandemia. Es decir, se reflexiona sobre el papel de la psicología crítica y de la crítica a la psicología en tiempos de pandemia como referente para considerar la bien nombrada crisis de la crítica.

\section{La imposibilidad crítica de la psicología hegemonía}

Ya han pasado algunas décadas desde que fue lanzado el programa de la psicología crítica en los ámbitos académicos (WALKERDINE, 2001). Los investigadores preocupados por la situación de la disciplina y de la relación que ésta tenía con procesos sociales se dieron a la tarea de repensar caminos por medio de los cuales se pudiera formular una psicología de carácter crítico. Con mayor o menor resonancia en los distintos continentes se hicieron propuestas de diferente calibre. Varios congresos se llevaron a cabo, así como se hicieron publicaciones de libros y de nuevas revistas. La psicología crítica parecía estar en un momento vibrante de crecimiento en muchos lugares, tanto en el número de sus miembros, como en el orden conceptual y práctico (WALKERDINE, 2001). Particularmente, este impulso puso bajo examen diferentes ramas de las ciencias psi, cuestionó las 
prácticas psicológicas que se llevaban a cabo en los ámbitos institucionales, así como logró extender sus análisis e interrogantes hasta llegar a considerar la cotidianidad de la cultura psicológica (PARKER, 2007; PRILLELTENSKY, 1994).

Sin embargo, la psicología crítica no pareció tener ni el mismo interés, ni la misma repercusión en los temas relacionados con el trabajo. Si se consideran países como el Reino Unido, España y Estados Unidos, en donde oficialmente se dio impulso a un tipo de psicología crítica, salvo por algunas propuestas aisladas (PRILLELTENSKY, 1994; HOLLWAY, 1991; CRESPO-SUAREZ; SERRANO PASCUAL, 2011), el mundo del trabajo fue casi completamente dejado de lado (PULIDO-MARTINEZ; WALKERDINE, 2007). En este sentido, en la literatura se afirmaba que no había dentro de la psicología crítica una difusión similar a la que se presentaba en campos relacionados con la clínica, la educación o la sexualidad y el género (CABRUJA-UBACH, 2004; PULIDO-MARTINEZ; CARVAJAL-MARIN; CABRUJA UBACH, 2009; PULIDO-MARTINEZ; WALKERDINE, 2007). Diferentes motivos se traían a colación para explicar esta situación. Se señalaba que la carencia de investigación de corte critico estaba posiblemente vinculada con el desencanto que había traído el marxismo, durante las décadas de los años ochenta y noventa, a aquellos académicos comprometidos con el cambio, de manera tal que se había producido un desplazamiento del grueso de estudios hacia el terreno de la crítica cultural (PULIDO-MARTINEZ; WALKERDINE, 2007). Tambien se argumentaba que la empresa exitosa de la psicología vinculada con su afán de servir a los intereses de la gerencia de las organizaciones alcanzaba una posición soportada por instancias de poder que la hacían inexpugnable ante los cuestionamientos de muy diferente tipo que se le formularan dentro y fuera de la disciplina (BARITZ, 1960; MONTMOLLIN, 2004; PULIDO-MARTINEZ, 2004).

En este contexto, para examinar el estado de la psicología crítica y la posición asumida ante la pandemia actual, no se puede que la empresa psicológica hegemónica, industrial-organizacional sigue su marcha incólume ante las críticas que se le han formulado como se denota en publicaciones recientes (STEVENS; GIELEN, 2007; RICH et al., 2018). En términos amplios, alrededor del planeta las intervenciones de la psicología hegemónica siguen concentrándose en el mismo ciclo psicológico organizacional, del cual se puede decir, parte de la selección de personal, pasa por las intervenciones de diferentes tipos para la retención de los trabajadores en las organizaciones y termina con las recomendaciones para el retiro. Empero, recientemente esta psicología paulatinamente está siendo absorbida por aquellas perspectivas que piensan el trabajo alrededor del riesgo y los riesgos del trabajo como una cuestión psicosocial. Esto ha dado un matiz distinto a las intervenciones tradicionales, que ahora tienen que incluir conceptos como el burnout, la resiliencia, la personalidad robusta, y demás objetos psicológicos por el estilo. El estrés es, por supuesto, uno de los temas centrales que ahora de cierta forma subordina los procesos organizacionales tradicionales que componen el ciclo psicológico organizacional. Es decir, alrededor de conceptos que hacen referencia constante al estrés laboral y a los problemas del trabajo como fuente de este, los procesos tradicionales de reclutamiento, retención y retiro cada día tienen, en mayor medida, el encargo de dar cuenta de cómo contribuyen mitigar el estrés de los trabajadores (PULIDO-MARTINEZ; CARVAJAL-MARIN, 2015).

Es igualmente importante anotar que la psicología industrial-organizacional sigue compuesta por un conocimiento técnico desarrollado por y para la situación de empleo. Este tipo de conocimiento ha reflejado a lo largo de los años su contribución para llevar acabo los cambios que el capitalismo requiere. A este respecto basta con señalar como actualmente la psicología positiva, la programación neuro-lingüística y la promoción de la felicidade, de la autonomía y la autoorganización han ganado un amplio espacio para concebir a los trabajadores y para hacer intervenciones organizacionales basadas en propuestas individualizantes muy acordes con la flexibilización laboral, la desaparición del estado del bienestar y la disminución de la responsabilidad directa que tienen las organizaciones con el bienestar de los trabajadores. Entonces, no se puede dejar de señalar que el potencial transformador de la psicología industrial-organizacional ha sido grande, sin embargo, su capacidad crítica ha estado muy limitada, cuestión que le vale el aprecio de las oficinas de recursos humanos y de las gerencias alrededor del mundo, y seguramente de los gobiernos que actualmente enfrentan la pandemia.

Con la crisis que ha afectado en gran medida al trabajo, las respuestas de los psicólogos industriales organizacionales han estado referidas a hacer llamados para que, por ejemplo, las personas eviten el aburrimiento (RUIZ; ARCAÑO; PEREZ, 2020) mitiguen los efectos que puede generar la cuarentena y en encerramiento, y a hacer hincapié en que las personas deben dar cuenta de su estrés, que lo deben manejar y por tanto controlar. A la par, se hace énfasis en asuntos como la resiliencia que las personas tienen para enfrentar situaciones difíciles y demás cosas por el estilo (SALANOVA, 2020). Estos llamados a la intervención resaltan no por derivarse de análisis innovadores, por el contrario, aun ante situaciones tan complicadas como esta, se destacan por prescribir más de lo mismo que usa la psicología en los ámbitos caracterizados por el trabajo formal. No obstante, como de la práctica se deriva la crítica, se puede ver claramente cómo la psicología hegemónica en su visión alejada de las condiciones laborales y de la organización del trabajo, no tiene las herramientas para entender, o para proporcionar una perspectiva que conciba la pandemia como un fenómeno colectivo al que se le pueda dar algún tipo de respuesta que considere a los trabajadores en su conjunto y no de manera individual. Así, estos llamados a ser optimista, resiliente, "corajudo", a que se exploren las posibilidades del teletrabajo y todas las demás sugerencias que están haciendo los psicólogos, por loables que sean, se concentran y se devuelven sobre el afectado. De cierta forma, de nuevo trivializan los problemas del trabajo que ahora han 
sido traídos por la pandemia. Como siempre lo ha hecho, la psicología hegemonía se olvida de que las condiciones laborales juegan un papel central. Así, las estrategias que circulan apelando exclusivamente a la interioridad del trabajador, lo responsabilizan por lo que ocurre al olvidar que la vulnerabilidad, las incertidumbres y el estrés son también el resultado de procesos colectivos, económicos y sociales. Al hacer este tipo de separaciones la psicología hegemónica contribuye a suponer que las soluciones están en manos de los trabajadores y, por tanto, conduce a simplificar la complejidad del mundo laboral.

En esta mirada psicológica difícilmente cabe suponer que las soluciones puedan provenir de unas nuevas negociaciones entre el Estado, las organizaciones y los trabajadores, puesto que los problemas se conciben como asuntos de variables individuales que se ubican en la interioridad de aquellos que trabajan. La psicología al individualizar el mundo laboral en tiempos de pandemia con la fórmula "afróntelo lo mejor que pueda con sus recursos internos", sienta las bases para negar una posible negociación simétrica entre las instancias que regulan el trabajo, tales como los órganos gubernamentales, las organizaciones laborales y los sindicatos. Al personalizar los problemas que ha traído la pandemia, como consecuencia, se contribuye a cerrar un tanto la posibilidad de concebir que el bienestar y seguridad psicológicas en tiempos de crisis dependen directamente de las condiciones laborales reguladas, así como del cumplimiento de los derechos a la salud y al trabajo.

\section{La psicología social como alternativa crítica del trabajo}

Vale ante la presente situación volver a hacer una breve revisión de las psicologías que se constituyeron como alternativas críticas, de cierta forma opuesta a la psicología industrial organizacional. Estas psicologías asumen de antemano que no es posible pensar una relación entre la psicología y el trabajo que de una u otra manera no esté vinculada con el capitalismo y su correspondiente organización internacional, nacional y local. Las preguntas en estas versiones alternativas del conocimiento psicológico específicamente emergen de la forma en como psicología y trabajo se vinculan entre sí. Aquí, resulta esclarecedor y conveniente revisar los argumentos formulados por Bernardo et al. (2017) cuando señalan los orígenes históricos distintos de las tradiciones que en psicología se ocupan del trabajo. La psicología industrial organizacional tuvo sus orígenes en la tradición inaugurada por Hugo Münsterberg y Elton Mayo en las sociedades del Atlántico norte; mientras que por ejemplo la psicología social crítica del trabajo en los países de Sudamérica hundió sus raíces en las formas en las que se apropiaron y desenvolvieron la medicina social y la psicología social latinoamericanas Se podría agregar que muchas de estas propuestas para hacer psicología establecieron igualmente vínculos estrechos con las formas en que se ha elaborado localmente el pensamiento social europeo tanto del estilo desarrollado por la escuela de Frankfurt, como del psicoanálisis de corte más sociológico.
Por tanto, esta relación entre la psicología y el trabajo siempre ha estado interesada, por un lado, en concebir el trabajo, y la salud laboral, como fenómenos psicosociales, complejos y determinados por las relaciones de poder (LAURELL, 1978; OREJUELA; PEREZ; VÁSQUEZ, 2019); y, por otro lado, ha estado particularmente preocupada por aquellas formas de laborar que no se incluyen, o cobijan, bajo la forma empleo, así como por relación de mutua dependencia entre el trabajo regulado y el que no lo está. Su accionar está tanto dirigido a considerar y movilizar cambios en las condiciones laborales, como en promover una cierta liberación del trabajador. La categoría trabajo estructura un marco conceptual que permite comprender, tanto las formas, como las relaciones de la organización de este a distintos niveles, internacionales, Estatales, sociales, organizacionales y por supuesto también psicológicos (BENDASOLLI; FALCAO, 2013; BURBANO-VALENTE, 2013; GOMEZ-VELEZ, 2016). En este mismo modo, a partir de la categoría identidad-subjetividad en estas psicologías críticas se deriva una visión holística de los trabajadores que hace énfasis en los cambios en la organización del trabajo y las maneras en cómo se conciben y son concebidos aquellos que laboran (STECHER; ROY, 2019; STECHER, 2013; COUTINHO; BERNARDO; SATO, 2017; SCOPINHO, 2013; ALTAMIRANO; ROY, 2013; PÉREZ; MALVEZZI, 2018). Por supuesto, esta manera de hacer psicología que se convierte en crítica del mundo del trabajo no hace una reivindicación romántica de las formas de laborar que se han invisibilizado. Mas bien se trata de utilizar herramientas conceptuales como poder, dominación, proceso de trabajo, inequidad, exclusión, precarización, plusvalía, salud laboral, conflicto, alienación, ideología, identidad-subjetividad y clase, para examinar y destituir las aparentes polaridades que se han hecho desde las Universidades, las cuales separan el trabajo formal e informal, el rural y el urbano, entre el trabajo no regulado y el que no lo está y entre la salud laboral y la economía (COUTINHO; BERNARDO; SATO, 2017; OREJUELA; PEREZ; VASQUEZ, 2019; SPINK, 2004; LAURELL, 1978; MARTIN-BARÓ, 1989; BORGES-ANDRADE; PEREZ; TORO, 2018; PULIDO-MARTÍNEZ, 2013; VARGAS-MONROY, 2019). Entonces, el análisis de esta psicología parte de las condiciones laborales, entre las que se cuentan aquellas relacionadas con la forma social empleo, y esas otras que están atadas al trabajo no regulado en América Latina y que se constituyen, en algunos países, en las condiciones en que labora más de la mitad de la población de trabajadores (RUIZ; GONZALEZ; ROJAS, 2019).

En esta perspectiva, al hacer referencia al estado de la crítica cuando se enfrenta con la situación actual, se puede decir que a diferencia de las recomendaciones hechas por los psicólogos que siguen la corriente hegemónica, el reto ha estado relacionado con el mantenimiento de los derechos al trabajo y a la salud. Los análisis que se proveen desde estas psicologías críticas no están dirigidos a intervenir a los trabajadores para que sepan cómo manejar la situación difícil por la que se atraviesa, por 
el contrario, se trabaja con ellos para enfrentar la acelerada precarización e intensificación del trabajo que está teniendo lugar a raíz de la pandemia. La perspectiva crítica de la psicología entonces asume la situación de crisis desde un punto de vista de la vulnerabilidad colectiva (BRAZ, 2020). Se aleja así la responsabilización de cada trabajador por su salud y por su sufrimiento psíquico. En su lugar, las inequidades que están presentes en la sociedad en general y en el mundo del trabajo en particular son eje de los análisis que se llevan a cabo.

Específicamente, en un momento en donde se relajan las medidas con respecto al control de la expansión del virus Covid-19, la reflexión vuelve sobre las estrategias de contención y sobre aquellos afectados para señalar tanto las desigualdades que se reeditan con relación al trabajo, como la posición que tienen los trabajadores en la sociedad, para desde ahí entender las afectaciones que tienen con el sufrimiento psíquico (BRAZ, 2020). Entonces se destaca la situación de los trabajadores en las condiciones no reguladas de trabajo en las manufacturas y en la construcción, asi como se considera el trabajo de los vendedores ambulantes y domestricos, quienes resultan ser más afectado por las condiciones de trabajo y de incertidumbre. Son estos trabajadores a los que se les da "vía libre" para que regresen al trabajo. Esta realidad resulta fundamental para pensar de manera crítica los problemas que pueden afectar al trabajador, así como también para considerar las posibles salidas que desde la psicología se puedan proporcionar para mitigar la crisis (RODRÍGUEZ-BAILÓN, 2020).

La psicología crítica como punto de vista alternativo aquí, ante la pandemia se interesa de manera central por crear opinión pública (COUTINHO; BERNARDO; SATO, 2017). En este sentido, los análisis buscan mostrar cómo la pandemia refleja "lo que somos", en términos de inequidad, discriminación, falta de acceso a la salud y condiciones diferenciadas de trabajo y clase social. Como consecuencia, se busca concebir y hacer circular una serie de argumentos para que se abran posibilidades de acciones afirmativas de corte colectivo. La visión de la psicología hegemónica industrial-organizacional que favorece dar herramientas para que las personas respondan "haciendo lo que puedan de manera individual", conduce a una visión de aislamiento empoderado, por el contrario, las posibles intervenciones que surjan aquí van dirigidas a todos los trabajadores en una sociedad afectada, donde la soluciones propuestas en muchas oportunidades por las entidades reguladoras y por las organizaciones laborales, buscan deteriorar aún más las condiciones laborales exacerbando, de esta forma, la vulnerabilidad de los trabajadores.

\section{La psicología como problema en la crisis}

Los dos tipos anteriores de relaciones que la psicología ha configurado con el mundo del trabajo establecen un juego que ha sido criticado también desde perspectivas que quieren hacer un conocimiento crítico que se aparte de la psicología misma. Allí la relación que se propone señala que tanto la psicología industrial-organizacional como las alternativas críticas más que antagónicas resul- tan de cierta manera complementarias en el mundo del trabajo. Las psicologías del riesgo y las del ciclo organizacional; las psicologías de la felicidad y del sufrimiento, sin llegar a ser un espejo una de la otra, muestran aspectos de la cultura que les dio lugar, al punto que se puede afirmar, como lo hace Nikolas Rose (1996) que más que antagonistas pueden verse en términos de una complementariedad del mercado para todo el que requiera intervenciones de corte psicológico. Esta particularidad de la psicología tiene como consecuencia que sea difícil pensar los problemas de los sujetos que trabajan por fuera de este conocimiento que se muestra diverso, pluri-paradigmático, epistemológicamente distinto, y con intervenciones muy variadas a lo largo de ramas y propuestas que componen a las ciencias psi. Pero este no es el único, ni el mayor problema que se señala desde aquí. También se muestra que las diversas formas de considerar al trabajo y a los trabajadores a través de las herramientas psicológicas, permite que se generen problemas, que se fijen estos a las maneras de describirlos y que sea posible intervenirlos, y que a la vez se formulan uma serie de criticas a estos puntos con las herramientas que la psicología en su conjunto provee (BURBANO-VALENTE, 2016; HOLLWAY, 1991; PULIDO-MARTINEZ, 2007).

Esta tradición de la crítica a la psicología se establece, no solamente pero también en relación con el mundo laboral, a partir del trabajo que Michel Foucault propuso y que fue seguido por Robert Castel, Fernando Álvarez-Uría, Wendy Hollway y el mismo Nikolas Rose. Aquí la psicología se convierte en un conocimiento que es menos liberador y más útil para que el capitalismo funcione correctamente produciendo al sujeto que es fundamentalmente un trabajador. Señalan los investigadores en esta perspectiva que una de las formas en las cuales la psicología contribuiría, a calibrar los mecanismos del sistema capitalistas para no se detengan ni pierdan su eficacia estaría precisamente vinculada con la complementariedad entre las perspectivas hegemónicas y críticas de la disciplina (ROSE, 1996, 1999). Entonces esta manera de examinar el lugar y las operaciones de la psicología, como cuerpo de discursos y prácticas, asume que estas formas de producir conocimiento entre convencional y progresista, entre sostenedores del estatus quo y apoyadores de los cambios sociales, se traduce entre buenas y malas psicologías (obviamente dependiendo del lado en que se ubique el investigador), así se deja por fuera, o mejor se dificulta, que pueda considerarse que quizá uno de los problemas del mundo del trabajo sea precisamente que está intervenido por muchas clases de psicologías. Esto sucede al punto que actualmente se ha naturalizado que las formas de pensar psicológicas son la enfermedad y el remedio para los problemas del trabajo que tienen directa relación con las personas.

La psicología por ejemplo provee el lenguaje para que se entienda al trabajador tanto desde las perspectivas gerenciales como críticas. En la primera se puede traducir la subjetividad a una serie de números para hacer ejercicios de gobierno que tienen un carácter ético a la luz de los valores de la competencia del mercado y en 
la segunda se muestran las implicaciones éticas que esta operación tiene a partir de la crítica de la psicología que supone la alienación del trabajador. En este inter-juego se configura una política en la que la psicología es una herramienta o un vehículo para el ejercicio de gobierno de acuerdo con las racionalidades imperantes. La más reciente y considerada ampliamente en la literatura seria aquella atada al neoliberalismo, la cual justamente se hace más visible desde que emergió la pandemia.

En esta perspectiva de la crítica, los investigadores consideran la relación psicología trabajo de un modo que no se detiene exclusivamente en los límites de los ámbitos en donde se labora (MILLER; ROSE, 2008). A este respecto se puede mencionar como en el análisis de la biopolítica contemporánea se examina el trabajo para poner de presente la relación entre aquellos que están muriendo en mayor medida, quienes son, por diferentes razones, aquellos que han salido o están por salir del mundo del laboral. Y en este sentido se muestra que hay una especie de celebración necro-política en los medios de comunicación cuando reiteran una y otra vez, que los jóvenes están de cierta forma menos en riesgo y hasta son inmunes al virus que causa la pandemia. Como señala Pinzón (2020), se puede vincular esta situación con los debates que antecedían acerca de la necesidad de desvincular al Estado de la seguridad social, y se podria afirmar, especialmente de las discusiones relacionados con la seguridad social que ahora le han dado el nombre de "carga pensional". En esta misma línea, se puede señalar aquí cómo la construcción de las identidades sociales se torna política al dividir la población de acuerdo con ciertas características supuestamente intrínsecas a los sujetos para hacerlos gobernables. Con el tipo de descripciones que circulan en la cultura psicológica amplia, hay unos que deciden sobre otros en términos de descripciones que anonimizan, tal como aquella que se le asigna en mucho por la situación, a las personas que salieron del trabajo y/o a aquellos que ya no están en edad de laborar, a los cuales se les llama constituyéndolos como grupo vulnerable e inviable políticamente, llamándolos con términos tales como "abuelitos".

Igualmente, la política neoliberal en términos de la pandemia no parece detenerse solamente a formular quienes deben integrarse en primera línea al trabajo. Según Vilarinho (2020), la politica neoliberal actua nuevamente como necropolitica con la consecuencia de que con la crisis se hace patente que el aseguramiento social no se le puede dar tramite dentro de un modelo de gestion que llama a las libertades del sujeto que es obviamente psicológico. Unicamente queda en esta manera del ejercicio politico, una muestra desprecio por la vida de los trabajadores. En palabras de Vilarinho (2020), la tecnologia de gobierno hace un corte entre los que deben morir y los "ciudadanos de bien", entre los que pueden vivir y los que "mueren en cuanto tienen que morir". En esta misma la linea, no pasa desapercibido el discurso de guerra cuando se trata de enfrentar la pandemia. La guerra se libra contra el enemigo invisible con una estrategia de una militarizacion simbolica de la "cuestion social" que se pone en circulación (CASTELO, 2014). Los objetos psicológicos acompañan la estrategia militarista. En esta guerra se apela a una cierta constitución de la psicología popular para poder llamar "debiles" a quienes no salen a enfrentar el peligro de morir. Al ponerse en práctica este discurso, las diferencia de clase patentes en quienes se integran al trabajo y quienes pueden permanecer en confinados en lugares seguros se manifiestan nuevamente. Así, los pobres en general serán aquellos que caerán en mayor medida en esta guerra en la cual a los profesionales de las ciencias psi, no parece quedarles mayor opción que prepararse para orquestar con su ayuda a llevar a cabo descripciones patologizantes como el "síndrome de la cabaña", y a diseñar intervenciones para superar el estrés postraumático que puede acompañar el tipo de situaciones que la pandemia genera cuando se describe en términos guerreristas.

\section{Relaciones internacionales y psicología}

Todavia hay una perspectiva crítica que no ha sido considerada hasta aquí. Esta última forma de examinar la relación que la psicología ha establecido con el trabajo está vinculada con las dimensiones locales e internacionales en las que el complejo psi se presenta a nivel global. Es una forma de analizar a la psicología que se ejerce por ejemplo, al resaltar que, tanto el conocimiento psicológico, cómo las críticas que a el se le formulan, asumen una perspectiva universalizante, la cual lleva a suponer, por ejemplo, que el capitalismo tiene, sino iguales muy similares manifestaciones alrededor del mundo (PULIDO-MARTINEZ; SATO, 2013; PULIDO-MARTINEZ; BURBANO-VALENTE, 2017). Esta es una manera de examinar al conocimiento psicológico que quiere dar cuenta de la relación de éste con el mundo laboral dentro de un modelo en donde el capitalismo tiene diferencias, similitudes y conexiones distantes en términos de sus manifestaciones y de los usos posibles de la psicología en diferentes países. Se asume que existen discrepancias, señaladas en la literatura como rivalidades geopoliticas en torno a la producción del conocimiento psicológico lo cual da origen, al menos a, tres o cuatro mundos de la psicología (MOGHADDAM, 1987, 2006; PULIDO-MARTINEZ, 2017, 2019); cómo tambien a apropiaciones singulares y a reconfiguraciones hibridas de los objetos psicológicos para hacer efectivas las prescripciones para la organización internacional del trabajo (RIVERA-AGUILERA, 2018), y en esta medida entran en relación con las instituciones globales, los Estados nacionales, las organizaciones particulares y los trabajadores en condiciones laborales reguladas y no reguladas (RIVERA AGUILERA, 2018; PULIDO-MARTINEZ, 2017, 2019).

Solamente se pueden aqui mencionar algunos puntos generales en relacion con la pandemia, pues esta manera de relacionar la psicología con el trabajo todavia no ha sido explorada de manera amplia por las perspectivas críticas. Sin embargo, se presentan algunas referencias en la literatura que pueden mostrar la pertinencia de empezar a examinar lo puede estar ocurriendo en esta perspectiva. Lo que se deja ver de las relaciones internacionales de la psicología es una reedicion de lo que ya se habia 
establecido desde hace varias decadas. Esto esto es, que hay unos centros de producción de conocimiento y otros lugares periféricos a donde estos discursos y prácticas psicológicas viajan para ser adaptados y apropiados para la situacion local (PULIDO-MARTINEZ, 2017). En relacion con la pandemia especificamente se señala en la literatura que los conocimientos de la ciencia ahora internacionalizados cruzan las fronteras sin dificultades, cuestión que lleva a que la situacion universal en donde todo el mundo está en riesgo, se convierte en vía privilegiada para que se apliquen los conocimientos que resultan acordes al modelo imperante de racionalidad económica. No es gratuito entonces que para afrontar la pandemia se tomen medidas psicológicas de diferentes tipos y a que se reproduzcan en diferentes partes las mismas recetas. A esto contribuye en la situacion de pandemia, como bien ha sido señalado en la literatura (KLEIN, 2007), que no sea solamente la llegada de los expertos quienes prescriben que hacer acorde con la racionalidad neoliberal de gobierno, sino que en este caso sean las nuevas tecnologías las que diseminan mas rápidamente los discursos y prácticas psicológicas para su pronta aplicación $\mathrm{y}$, de cierta forma subordinación, de los conocimientos que se han desarrollado localmente.

\section{Conclusión}

Este articulo se propuso examinar el estado de la crítica y de la psicología crítica cuando se encargan de examinar el mundo del trabajo en relacion con la crisis que ha suscitado la pandemia. De manera general se ha considerado el esfuerzo crítico en tiempos complejos para encontrar el lugar que este tiene en referencia al lugar y las operaciones que se llevan a cabo gracias a la psicología. A lo largo del texto se ha visto como las perspectivas críticas han asumido una posicion de contra-psicologías asumiendo una postura política que las aparta de las corrientes recomendaciones que pululan desde la psicología convencional, las cuales casi exclusivamente, compelen al trabajador para que considere las dificultades de la pandemia de forma individual. Los analisis provistos por las psicologías de corte crítico más bien muestran como la pandemia ha traido mayor vulnerabildiad colectiva. Ellas toman una posicion en donde los analisis políticos economicos, sociales y culturales son la base para entender los problemas, por ejemplo, de salud mental que emerjen con la cuarentena. Al concentrarse en los procesos que diferente orden afectan al trabajo y por ende a los trabajadores, las psicologías críticas abren la posibilidad de construir los problemas como un asunto colectivo, y por tanto, tambien abren la posibilidad de encontrar soluciones que tengan dimensiones en esta línea.

Tambien, las críticas a la psicología han señalado como esta disciplina esta vinculada con la racionalidad de gobierno imperante que en el caso de la pandemia deja entrever una necropolitica asociada al neoliberalismo que lejos de ser una perspectiva idealizada en la practica sirve para decidir quienes viven y quienes mueren de acuerdo con las logicas del capital. Esta perspectiva apenas empieza a formular propuestas para comprender la situacion, tal como tambien ocurre con aquellos analisis que se encargan de revisar las relaciones internacionales que tienen lugar en la producción y consumo de la psicología,

La revision que a lo largo del texto se hizo muestra la pertinencia de la crítica como fuerza alternativa que cuestiona lo que se da por hecho como intervenciones apropiadas para aportar a la situacion de crisis. Tanto la psicología crítica, como las críticas a la psicología, son muestran alternativas a las intervenciones de la psicología hegemonica, estan politicamente comprometidas, $\mathrm{y}$ por tanto no se dirijen a mitigar los problemas que presenta el estatus quo, sino que por el contrario, con una perspectiva amplia examinan como las condiciones de trabajo vulnerabilizadas estan a la base de las diferencias en las cuales se esta portando la pandemia.

No obstante, en esta revision tambien se denota la crisis de la crítica con respecto al trabajo. Si bien las instituciones que regulan a la psicología, las agremiaciones y las universidades mismas se han puesto en la tarea divulgar prescripciones hegemonica para intervenir en el pandemia a traves de distintos medios, las perspectivas críticas, por el contrario, han permanecido un tanto silenciosas, aun cuando se encuentran referencias en la literatura estas no son abundantes como aquellas otras de corte mas conservador. Quiza por el tipo de analisis y de materiales que demandan los estudios criticos, como tambien por la explicita intencion de no realizar prescripciones sin comprensiones politicas y sociales particulares que puedan caer en futurologias inciertas que aminoren la potencialidad critica, no se han hecho mayores pronunciamientos. Habra que abrir un compas de espera para poder hacer anotaciones mas precisas sobre el estado y la potencia de la crítica con respecto a la relacion que la psicología ha establecido con el mundo del trabajo en condiciones de pandemia.

\section{Información sobre los autores:}

Hernán Camilo Pulido-Martínez, Ph. D.

(iD) https://orcid.org/0000-0003-1071-2784

https://scienti.minciencias.gov.co/cvlac/visualizador/ 消'

Profesor titular y director de postgrados en la Pontificia Universidad Javeriana en Bogotá, Colombia. Doctor en Ciencias Sociales por la Cardiff University en el Reino Unido. Magister en Comunicación y Psicólogo de la Pontificia Universidad Javeriana. Coordinador del grupo de investigación "Estudios críticos de las organizaciones y del trabajo", clasificación A, Colciencias.

\section{Johanna Burbano-Valente}

(iD) https://orcid.org/0000-0002-4011-2117

https://scienti.minciencias.gov.co/cvlac/visualizador/ 消焦 generarCurriculoCv.do? cod rh=0000151270

Decana Facultad de Psicología, Pontificia Universidad Javeriana en Bogotá, Colombia. Doctora en Psicologia por la Universidad de Buenos Aires. Magister en Estudios Políticos y Psicóloga de la Pontificia Universidad Javeriana. Miembro del grupo de investigación "Estudios críticos de las organizaciones y del trabajo", clasificación A, Colciencias. 


\section{Contribuição dos autores:}

Hernán Camilo Pulido-Martínez foi responsável pela concepção, desenho, análise e interpretação dos estudos revisados. Johanna Burbano-Valente participou da concepção, desenho e revisão. Os autores aprovaram a versão final do artigo.

\section{Como citar este artigo:}

\section{ABNT}

PULIDO-MARTÍNEZ, Hernan Camilo; BURBANO-VALENTE, Johanna. La crítica de la psicología, trabajo y la pandemia de Covid-19. Fractal: Revista de Psicologia, Niterói, v. 32, n. 3, p. 318-327, set./out. 2020. https://doi.org/10.22409/1984-0292/ v32i3/45576

\section{APA}

Pulido-Martínez, H. C., \& Burbano-Valente, J. (2020, Setembro/ Outubro). La crítica de la psicología, trabajo y la pandemia de Covid-19. Fractal: Revista de Psicologia, 32(3), 318-327. doi: https://doi.org/10.22409/1984-0292/v32i3/45576

\section{Copyright:}

Copyright (C) 2020 Pulido-Martínez, H. C., \& Burbano-Valente, J. Este é um artigo em acesso aberto distribuído nos termos da Licença Creative Commons Atribuição que permite o uso irrestrito, a distribuição e reprodução em qualquer meio desde que o artigo original seja devidamente citado.

Copyright (C) 2020 Pulido-Martínez, H. C., \& Burbano-Valente, J. This is an Open Access article distributed under the terms of the Creative Commons Attribution License, which permits unrestricted use, distribution, and reproduction in any medium, provided the original article is properly cited.

\section{Referencias}

AGAMBEN Giorgio et al. Sopa de Wuhan. La Plata: ASPO, 2020. Disponible en: http://www.encurtador.com.br/dozBN. Accedido en: 12 set. 2020

ALTAMIRANO, Tomas Gaete; ROY, Álvaro Soto. Tensiones en la construcción identitaria individualizada en el trabajo flexible. Univesitas Psychologica, Bogotá, v. 12, n. 4, p. $1167-$ 1180, 2013. http://doi.org/10.11144/Javeriana.UPSY12-4.tcii

BARITZ, Loren. The servants of power: a history of the use of social sciences in american industry. Middletown: Wesleyan University Press, 1960.

BENDASOLLI, Pedro F.; FALCÃO, Jorge da Rocha. Psicologia social do trabalho sujo: revendo conceitos e pensando em possibilidades teóricas para a agenda da psicologia no contexto de trabalho. Universitas Psychologica, Bogotá, v. 12, n. 4, p. 1153-1166, oct./dec. 2013. https://doi.org/10.11144/ Javeriana.upsy 12-4.psts

BERNARDO, Marcia Hespanhol et al. Linhas paralelas: as distintas aproximações da psicologia em relação ao trabalho. Estudos de Psicologia, Campinas, v. 34, n. 1, p. 15-24, mar. 2017. http://dx.doi.org/10.1590/1982-02752017000100003

BORGES-ANDRADE, Jairo Eduardo; PEREZ, Erico Renteria; TORO, Juan Pablo. Organizational/work psychology in Latin America. In: ARDILA, Ruben (Ed.). Psychology in Latin America: current status, challenges and perspectivas. Gewerbestrasse: Springer, 2018. p. 105-158. https://doi org/10.1007/978-3-319-93569-0_7
BRAZ, Matheus Viana. A pandemia de Covid-19 (SARSCoV-2) e as contradições do mundo do trabalho. Revista Laborativa, v. 9, n. 1, p. 116-130, 2020. Disponível em: https:// www.encurtador.com.br/cwMP9. Acesso em: 10 jun. 2020 .

BURBANO-VALENTE, Johanna. Logicas colectivas en el servicio público de transporte de pasajeros en Bogotá. Universitas Psychologica, Bogotá, v. 12, n. 4, p. 1049-1059, 2013. https://doi.org/10.11144/Javeriana.UPSY12-4.lcsp

BURBANO-VALENTE, Johana. Discursos y prácticas de selección en los manuales de gestión humana. In: MARÍN, Luz Mery Carvajal; CÓRTES, Óscar Andrés López (Org.). Selección de personal: discursos, prácticas, tecnologías. Bogotá: Pontificia Universidad Javeriana, 2016. p. 51-69.

CABRUJA-UBACH, Teresa. Violencia doméstica: sexo y genero en las teorias psicosociales sobre la violencia. Hacia otras propuestas de comprension e intervención. Intervencion Psicosocial: Revista sobre lgualdad y Calidad de Vida, Madri,

v. 13, n. 2, p. 141-153, 2004. Disponible en: https://journals. copmadrid.org/pi/art/abdbeb4d8dbe30df8430a8394b7218ef. Accedido en: 22 ago. 2020.

CASTELO, Rodrigo. Crise conjuntural e (re)militarização da "questão social" brasileira. Revista Margem Esquerda, v. 23, p. 46-51, 2014. Disponível em: http://www.unirio.br/unirio/ cchs/ess/Members/rodrigo.castelo/artigos/crise-conjuntural-ere-militarizacao-da-questao-social-brasileira/view. Acesso em: 8 jun. 2020.

CHRISTIE, Catharine; LANZA, Edison; CAMILLERI, Michael. Covid-19 y la libertad de expresión en las américas. Washington: Dialogo Interamericano, 2020. Disponible en: https://www.thedialogue.org/wp-content/uploads/2020/08/ Covid-19-y-la-Libertad-de-Expresio\%CC\%81n-en-lasAme\%CC\%81ricas-SP-Final.pdf. Accedido en: 8 abr. 2020.

COUTINHO, Maria Chalfin; BERNARDO, Marcia Hespanhol; SATO, Leny. Psicologia Social do Trabalho. São Paulo: Vozes, 2017.

CRESPO-SUAREZ, Eduardo; SERRANO-PASCUAL, Amparo. Regulacion del trabajo y el gobierno de la subjetivdad. La psicologizacion politica del trabajo. In: BERNAL, Anastasio Ovejero (Coord.). Psicología Social Crítica. Madrid: Biblioteca Nueva, 2011. p. 246-263.

DELANTY, Gerard. The university in the knowledge society. Organization, v. 8, n. 2, p. 149-153. 2001. https://doi. org/10.1177/1350508401082002

FASSIN, Didier. How is critique? In: FASSIN, Didier; HARCOURT, Bernard E. (Org). A time for critique. New York: Columbia University Press, 2019. p. 13-35.

GOMEZ-VELEZ, Maria Alejandra. Sobre la psicología organizacional y del trabajo en Colombia. Revista Colombiana de Ciencias Sociales, v. 7, n. 1, p. 131-153, ene./jun. 2016. Disponible en: https://www.funlam.edu.co/revistas/index.php/ RCCS/article/view/1438/pdf. Accedido en: 2 feb. 2018.

HOLLWAY, Wendy. Work psychology and organizational: managing he individual at work. Londres: Sage, 1991.

IBARRA-COLADO, Eduardo. Educación superior, entre el mercado y la sociedad: apuntes para imaginar su función social. Revista de Educación Superior, México, v. 35, n. 138, p. 123133, jun. 2006. Disponible en: http://www.scielo.org.mx/scielo. php?script=sci arttext\&pid=S0185-27602006000200123\&lng $=$ es\&nrm=iso. Accedido en: 10 jul. 2020. 
KLEIN, Naomi. La doctrina de shock: el auge del capitalismo del desastre. Buenos Aires: Paidos, 2007.

LAURELL, Asa Cristina. Proceso de trabajo y salud. Cuadernos Politicos, México, n. 17, p. 59-79, jul./sep. 1978. Disponible en: http://www.cuadernospoliticos.unam.mx/cuadernos/contenido/ CP.17/17.7.AsaCristina.pdf. Accedido en: 20 sep. 2012.

MARTÍN-BARÓ, Ignácio. Psicología política del trabajo en America Latina. Revista de Psicología de El Salvador, v. 8, n. 31, p. 5-25, 1989.

MILLER, Peter; ROSE, Nikolas. Governing the present. Cambridge: Polity, 2008.

MOGHADDAM, Fathali. Psychology in the three worlds: as reflected by the crisis in social psychology and the move toward indigenous third-world psychology. American Psychologist, v. 42, n. 10, p. 912-920, 1987. https://doi.org/10.1037/0003066X.42.10.912

MOGHADDAM, Fathali. Double reification: the processes of universalizing psychology in the three worlds. In: BROCK, Adrian (Org.). Internationalizing the History of Psychology. New York: University Press, 2006. p. 163-182. Disponible en: http://fathalimoghaddam.com/?page id=18. Accedido en: 15 out. 2020 .

MONTMOLLIN, Maurice de. Psicofarsantes: una autocrítica de la psicología industrial. México: Siglo XXI, 2004.

OREJUELA, Jhonny; PEREZ, Maria del Mar; VÁSQUEZ, Andrés. Trabajo, subjetividad y clinicas del trabajo: una aproximación al estado de su cuestion en el caso colombiano. Open Edition Journals, v. 15, n. 2, p. 1-24, 2019. https://doi. org/10.4000/laboreal.15522

PARKER, Ian. Revolution in psychology: alienation to emancipation. Londres: Pluto, 2007.

PÉREZ, Erico Rentería; MALVEZZI, Sigmar. Psicologías organizacionales y de los trabajos - POTS: preguntas desde las realidades actuales del mundo del trabajo en America Latina. Psicología desde el Caribe, n. especial, p. 129-147, 2018. http://dx.doi.org/10.14482/psdc.35.4.158.77

PINZÓN, Monica. Personas y tiempo del COVID-19. Revista Analisis de la Realidad Nacional, Guatemala, v. 9, n. 181, p. 46-55, marzo 2020. Diponible em: http://ipn.usac.edu.gt/wpcontent/uploads/2020/04/IPN-RD-181.pdf\#page=46. Accedido en: 1 de jun. 2020.

PRILLELTENSKY, Isaac. Morals and politics of psychology. Albany: State University of New York, 1994.

PULIDO-MARTINEZ, Hernán Camilo. En búsqueda de una psicología crítica en los ambitos laborales. Universitas Psychologica, Bogotá, v. 3, n. 2, p. 213-222, 2004. Disponible en: $\quad$ https://docplayer.es/11733190-En-busqueda-de-unapsicologia-critica-en-los-ambitos-laborales.html. Accedido en: 2 sep. 2016.

PULIDO-MARTINEZ, Hernán Camilo. Produciendo trabajadores modernos: conocimiento psicológico y el mundo del trabajo en el Sur. Universitas Psychologica, Bogotá, v. 6, n. 1, p. 27-37, ene./abr. 2007. Disponible en: https://revistas. javeriana.edu.co/index.php/revPsycho/article/view/91. Accedido en: 2 abr. 2015.
PULIDO-MARTINEZ, Hernán Camilo. Outlining crítical psychology of work in Latin America. Annual Review of Crítical Psychology, v. 10, p. 672-689, 2013. Disponible em: https://www.encurtador.com.br/fjwW6. Accedido en: 2 mayo 2019.

PULIDO-MARTINEZ, Hernán Camilo. De la expansión internacional de la psicología a la simultaneidad de procesos: o de la investigación sobre la subjetividad en el trabajo. In: PAVON-CUELLAR, David (Org). Capitalismo y psicología crítica en lationamerica: del sometimiento neocolonial a la emencipación de subjetividades emergentes. México: Kanakil, 2017. p. 243-264.

PULIDO-MARTINEZ, Hernán Camilo. Analysing the artefacts to produce an education of quality: from the disciple to the customer in a Colombian university. Subjectivity, v. 12, n. 1, p, 352-370, 2019. https://doi.org/10.1057/s41286-019-00081-w

PULIDO-MARTINEZ, Hernan Camilo; CARVAJAL-MARIN, Luz Mery. La patologización y despatologización de la ficción del "trabajador libre" em terminos del riesgo psico-laboral. In: LEAL-FERREIRA, Arthur Arruda; MOLAS, Adriana; CARRASCO. Jimena (Org.). Psicologia, Tecnologia $e$ Sociedade: controvérsias metodológicas e conceituais para uma análise das práticas de subjetivação. Rio de Janeiro: NAU, 2015. p. 235-254.

PULIDO-MARTINEZ, Hernán Camilo; CARVAJAL-MARIN, Luz Mery; CABRUJA-UBACH, Teresa. El sinuoso fluir de la psicología crítica: una conversacion con Teresa Cabruja Ubach. Universitas Psychologica, Bogotá, v. 8, n. 3, p. 583-599, 2009. Disponible em: https://revistas.javeriana.edu.co/index.php/ revPsycho/article/view/609. Accedido en: 2 feb. 2015.

PULIDO-MARTINEZ, Hernán Camilo; SATO, Leny. ...Y entonces ¿esto de la crítica que es? Universitas psychologica, Bogotá, v. 12, n. 4, p. 1355-1368, 2013. https://doi.org/10.11144/ Javeriana.UPSY12-4.rpmt

PULIDO-MARTINEZ, Hernán Camilo; VALENTE, Johanna Burbano. Formas de subordinacion geopolitica en la seleccion de personal: los manuales de seleccion como techné. In: FRIAS, Pamela; SOTO-ROY, Alvaro. Seleccion de personas en organizaciones: aproximaciones eticas, estratégicas, conceptuales y metodológicas. Santiago de Chile: UAH, 2017. p. $227-254$.

PULIDO-MARTINEZ, Hernán Camilo; WALKERDINE, Valerie. Psicología, el mundo de trabajo y la subjetividad. Valerie Walkerdine en conversacion con Hernán C. PulidoMartinez. Universitas Psychologica, Bogotá, v. 6, n. 1, p. 185-194, 2007. Disponible em: https://revistas.javeriana.edu. co/index.php/revPsycho/article/view/105. Accedido en: 2 abr. 2015

RICH, Grant J. et al. Teaching psychology around the world. Newcastle: Cambridge Scholar Publishing, 2018.

RIVERA AGUILERA, Guillermo. La construcción discursiva del joven trabajador: un analisis crítico a las tendencias mundiales de empleo. Universitas Psychologica, Bogotá, v. 17, n. 1, p. 1-14, 2018. https://doi.org/10.11144/Javeriana.upsy171.cdjt

RODRÍGUEZ-BAILÓN, Rosa. La desigualdad ante el espejo del Covid-19. International Journal of Social Psychology, v. 35, n. especial, p. 61-71, 2020. https://doi.org/10.1080/021347 48.2020 .1796298 
ROSE, Nikolas. Inventing ourselves: psychology, power and regulation. Londres: Sage, 1996.

ROSE, Nikolas. Governing the soul: the shaping of the private self. Londres: Free Association Books, 1999.

RUIZ, Alexis Lorenzo; ARCAÑO, Kenny Diaz; PEREZ, Dionisio Zaldívar. La psicología como ciencia en el afrontamiento a la Covid-19: apuntes generales. Anales de la Academia de Ciencias de Cuba, La Habana, Cuba, v. 10, n. 2, p. e839, 2020. http://www.revistaccuba.sld.cu/index.php/revacc/ article/view/839/856

RUIZ, Angela Vieira; GONZALEZ, Cesar Andres Llanco; ROJAS, Luis Alberto Guevara. Desafiando la formación de psicólogos organizacionales desde una perspectiva de aprendizajes situados en el ámbito micro-empresarial peruano. Cuadernos de Administracion, Bogotá, v. 32, n. 58, 2019. https://doi.org/10.11144/Javeriana.cao.32-58.dfpo

SALANOVA, Marisa. How to survive Covid-19? Notes from organisational resilience (¿Cómo sobrevivir al Covid-19? Apuntes desde la resiliencia organizacional). International Journal of Social Psychology, v. 35. n, 3, p. 670-676, 2020. https://doi.org/10.1080/02134748.2020.1795397

SCOPINHO, Rosemeire Aparecida. Processo organizativo de assentamentos rurais: trabalho, condições de vida e subjetividades. Sao Paulo: Fapesp, 2013.

SPINK, Peter Kevin. Para alé $m$ da psicologia organizacional: nove textos escolhidos. São Paulo: Centro de Administração Pública e Governo, EASEP-FGV, 2004. Disponível em: https:/ www.researchgate.net/publication/293811582 Para Alem da Psicología_Organizacional nove textos escolhidos Versao Preliminar. Acesso em: 20 abr. 2017.

STECHER, Antonio. Un modelo critico-interpretativo para el estudio de las identidades laborales. Contribuciones a la investigacion psicosocial sobre trabajo y subjetividad en America Latina. Universitas Psychologica, Bogotá, v. 12, n. 4, p. 1311-1324, 2013. https://doi.org/10.11144/Javeriana. UPSY12-4.mcie

STECHER, Antonio; ROY, Alvaro Soto. Crisis and transformation of occupational identities in three sectors (retail, mining, state): contributions to understanding workplace subjectivities in neoliberal Chile. Subjectivity, v. 12, n. 4, p. 309-332, 2019. https://doi.org/10.1057/s41286-019-00080-x

STEVENS, Michael J; GIELEN, Uwe P. Toward a global psychology: theory, research, interventionand pedagogy. Mahwah, New Jersey: Lawrence Erlbaum Associates Publishers, 2007.

VARGAS-MONROY, Liliana. Relaciones gubernamentalidad/ colonialidad/trabajo: el caso de las transformaciones en el gobierno de las trabajadoras de la industria de flor cortada en Colombia, 1995-2012. Cuadernos de Administracion, v. 32, n. 58, 2019. https://doi.org/10.11144/Javeriana.cao.32-58.rgct

VILARINHO, Gabriel. A seguranca e o outro nos tempos de coronavirus. Revista Estudos Libertários, Rio de Janeiro, v. 2, n. 4, p. 1-10, 2020. Disponível em: https://revistas.ufrj.br/ index.php/estudoslibertarios/article/view/34524. Acesso em: 5 jul. 2020.

WALKERDINE, Valerie. Editorial. International Journal of Crítical Psychology, London, v. 1, n. 1, p. 9-15, 2001. 